\title{
OSTEOMIELITE CRÔNICA MULTIFOCAL RECORRENTE: RELATO DE CASO DE DOENÇA RARA
}

\section{CHRONIC RECURRENT MULTIFOCAL OSTEOMYELITIS: RARE DISEASE CASE REPORT}

Victor Vidal de Oliveira ${ }^{1}$, Yasmin Christine Galhardo de Carvalho ${ }^{1}$, Giuliane Sayuri Araujo Toome ${ }^{1}$, Rafaella Sousa Araujo ${ }^{1}$, Danilo Garcia Ruiz ${ }^{2}$.

\begin{abstract}
RESUMO
Introdução: A Osteomielite crônica multifocal recorrente (OCMR) é uma doença autoinflamatória que se caracteriza por ativação da imunidade inata. Acomete principalmente a metáfise de ossos longos em crianças, adolescentes e jovens, majoritariamente do sexo feminino. Exames radiológicos são essenciais para exclusão de diagnósticos diferenciais. Desenvolvimento: Este artigo descreve caso de paciente adolescente, masculino, com quadro de artralgia de joelho direito e história familiar de primeiro grau com psoríase, o que despertara a hipótese de espondiloartrite periférica. No entanto, os achados da ressonância magnética, biópsia óssea e as informações clínicas caracterizaram OCMR. O paciente teve boa resposta ao metotrexato. Considerações finais: Logo, torna-se importante destacar a importância da OCMR no diagnóstico diferencial de artropatias crônicas da infância e adolescência.
\end{abstract}

Palavras Chave: Osteomielite crônica multifocal recorrente; OCMR; imunidade inata; adolescente.
Citação: Oliveira VV, Carvalho YCG, Toome GSA, Araujo RS, Ruiz DG. (2021) Osteomielite crônica multifocal recorrente: relato de caso de doença rara Revista de Patologia do Tocantins, 8(1).

Instituição: ${ }^{1}$ Acadêmico do curso de Medicina da Universidade Federal do Tocantins, Palmas, Tocantins, Brasil;

2 Mestre em Clínica Médica, professor assistente do curso de Medicina da Universidade Federal do Tocantins.

Autor correspondente: Victor Vidal de Oliveira; Rua 3, no 51, Setor Cavalcantinho - Cavalcante/GO - CEP 73790-000.

Editor: Carvalho A. A. B. Medicina, Universidade Federal do Tocantins, Brasil.

Publicado: 12 de maio de 2021.

Direitos Autorais: (c) 2021 Oliveira et al. Este é um artigo de acesso aberto que permite o uso, a distribuição e a reprodução sem restrições em qualquer meio, desde que o autor original e a fonte sejam creditados.

Conflito de interesses: os autores declararam que não existem conflitos de interesses.

\begin{abstract}
Introduction: Chronic recurrent multifocal osteomyelitis (CRMO) is an autoinflammatory disease characterized by the activation of the innate immunity. It mainly affects the metaphysis of long bones in children, adolescents and young people, mostly female. Radiological examinations are essential for the exclusion of differential diagnosis. Development: This article describes a case of an adolescent male patient with arthralgia of the right knee and a first-degree family member with psoriasis, which awakened the hypothesis of peripheral spondyloarthritis. However, findings from magnetic resonance imaging, bone biopsy and clinical information characterized CRMO. The patient had a good response to methotrexate. Final considerations: Therefore, it is important to highlight the importance of CRMO in the differential diagnosis of chronic arthropathies in childhood and adolescence. Key words: Chronic recurrent multifocal osteomyelitis; CRMO; innate immunity; adolescent.
\end{abstract}




\section{INTRODUÇÃO}

A Osteomielite crônica multifocal recorrente (OCMR) é uma doença autoinflamatória de baixa incidência1. Distúrbios autoinflamatórios são caracterizados pela ativação da imunidade inata na ausência de altos níveis de anticorpos e, ao menos inicialmente, o não envolvimento de linfócitos não reativos ${ }^{2}$.

A doença afeta crianças, adolescentes e jovens adultos ${ }^{3}$. Com proporção de 4:1, favorece o sexo feminino. Considerada uma doença rara, apresenta prevalência de 1-2 casos por $1.000 .000^{4}$

O diagnóstico diferencial consiste em Osteomielite infecciosa, lesão óssea maligna (osteossarcoma, linfoma não-Hodgkin), benigna (osteoma osteóide), Histiocitose de células de langerhans e artropatias crônicas da infância e adolescência. Trata-se de diagnóstico de exclusão ${ }^{4}$.

Costuma afetar a metáfise de ossos longos, embora as lesões possam acometer qualquer região óssea. Outros órgãos também podem ser afetados, como a pele, pulmões e o trato gastrintestinal $^{5}$. Em torno de $8 \%$ dos pacientes podem apresentar pustulose palmoplantar e psoríase. Sua evolução é insidiosa e sua duração variável, com quadro de dor, limitação da mobilidade, possibilidade de sinais inflamatórios locais e, em menor frequência, sintomas gerais, como febre, astenia e perda de peso'.

Exames radiológicos são essenciais para excluir diagnósticos diferenciais. As lesões ósseas são radiolúcidas, osteolíticas ou escleróticas, mas podem permanecer normais nos estágios iniciais. Na fase inicial, a ressonância magnética possui alta sensibilidade, sendo capaz de identificar lesões silenciosas. Quando não esclarecido, realiza-se biópsia óssea²

O tratamento de primeira linha consiste no uso de Antiinflamatórios Não Esteroidais (AINE's) ${ }^{6}$. Outras alternativas são o uso de corticosteróides, metotrexato, bifosfonatos e inibidores de fator de necrose tumoral (TNF)- $\alpha^{7}$.

Descreve-se caso raro de OCMR em adolescente masculino e destaca-se sua importância no diagnóstico diferencial de artropatias crônicas da infância e adolescência.

\section{DESCRIÇÃO DO CASO}

Adolescente masculino de 13 anos com quadro de artralgia crônica de joelho direito que evoluiu para artrite de punho esquerdo e de tornozelos. Sem outras queixas ou doenças crônicas. Gestação, parto e desenvolvimento neurológico normais. Pai tem psoríase e avô paterno gota. Exame físico normal para os principais órgãos e aparelhos, bom estado geral, apenas revelava limitação da extensão dos punhos, dor e edema de tornozelos. Apresentava seis ênteses dolorosas.

Tinha marcadores inflamatórios elevados (VHS e PCR), mas HLA-B27 negativo. Foram investigadas e descartadas doenças infecciosas crônicas, autoimunes, miopáticas e metabólicas. As ressonâncias de punhos e tornozelos evidenciaram erosões corticais com intenso edema ósseo distais em rádio e tíbia bilaterais comprovando osteomielite. A biópsia óssea de punho esquerdo demonstrou processo inflamatório em atividade sem infecção. Foram consideradas as hipóteses de artrite idiopática juvenil e de artrite psoriásica, mas as informações clínicas, radiológicas e histopatológicas somadas à ausência de sinais clínicos de infecção concluem pelo diagnóstico raro de osteomielite crônica multifocal e recorrente. Houve resposta parcial aos anti-inflamatórios e boa resposta ao uso de metotrexato $10 \mathrm{mg} /$ semana.

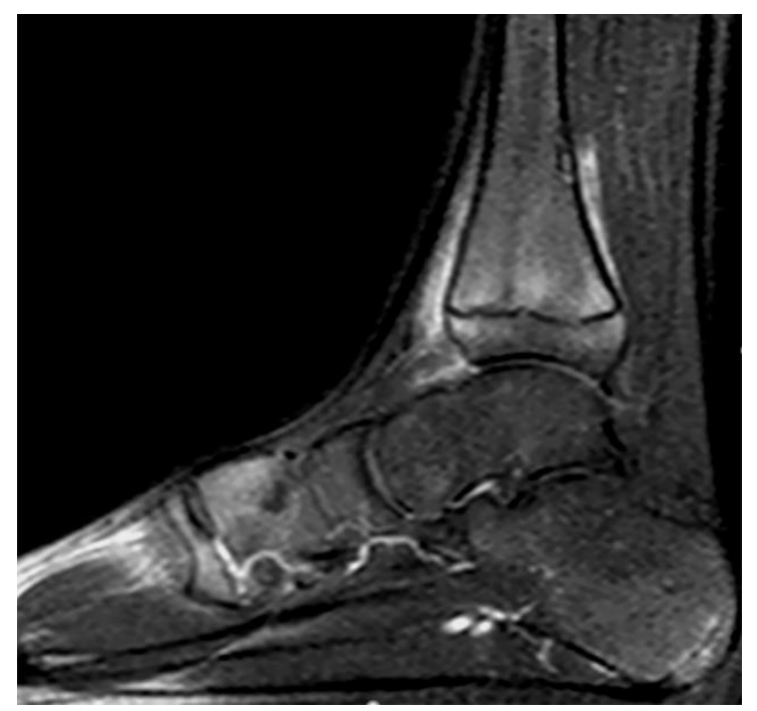

Figura 1. Edema medular ósseo com erosões corticais da placa epifisária distal da tíbia esquerda e sinais de periostite.

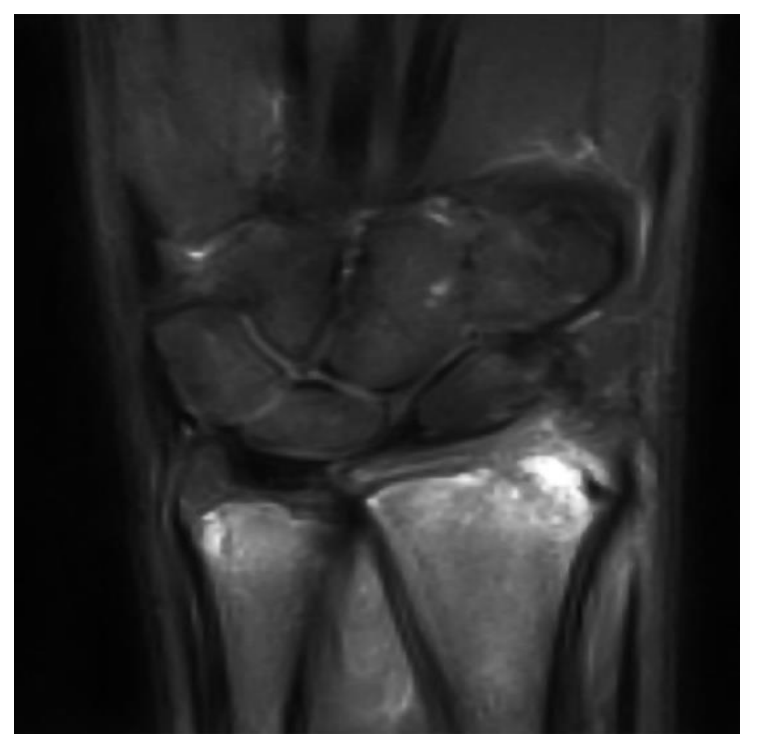

Figura 2. Erosões corticais com intenso edema da medular óssea nas placas epifisárias distais do rádio e ulna (punho direito).

\section{DISCUSSÃO}

A OCMR é uma entidade que costuma afetar indivíduos jovens, assim como o paciente relatado. Seu 
diagnóstico é feito a partir da exclusão de outros, dentre os quais neoplasias e infecções ${ }^{1}$. Tais diferenciais foram, neste caso, descartados a partir de correlações como biópsia de punho que não revelou agentes infecciosos ou células neoplásicas.

O quadro clínico é inespecífico, no entanto costuma afetar ossos longos e tubulares, sobretudo de membros inferiores, característica essa presente no caso estudado, no qual a ressonância demonstrou o acometimento erosivo do rádio e da tíbia, bem como de outras regiões como o punho, o que também ilustra a multifocalidade da doença ${ }^{8}$.

Analisando sob o ponto de vista dos critérios diagnósticos propostos por Jansson ${ }^{9}$ para osteíte não bacteriana, nosso paciente apresentava a prova radiológica alterada, o aspecto multifocal, bem como a biópsia estéril com sinais inflamatórios, além de critérios menores como história familiar de distúrbios autoimunes. Considerando a necessidade de ao menos dois critérios maiores para o diagnóstico, o caso em questão se encaixaria no cenário.

Os achados dos exames de imagem do paciente incluíram erosões corticais com intenso edema ósseo, o que também condiz com o exposto em pesquisas como a de von $K$ alle ${ }^{8}$. É importante lembrar, todavia, que a alteração em exames de imagem, apesar de ser um dos critérios maiores propostos para o diagnóstico da patologia, podem não estar presentes, sobretudo em fases iniciais. Podem, ainda, estar presentes e serem assintomáticas.

Em relação à terapêutica empregada, antiinflamatórios não esteroidais (AINE) permanecem sendo a primeira linha de tratamento. Outras opções descritas incluem corticóides, sulfassalazina e citocinas moduladoras ${ }^{10}$. O paciente em questão apresentou melhora parcial com o uso de AINEs, porém boa resposta ao metotrexato.

É importante ressaltar o achado frequente de condições inflamatórias crônicas e autoimunes em familiares dos pacientes com CRMO, o que vem ao encontro da hipótese de bases genéticas para seu desenvolvimento ${ }^{10}$. Até o momento, no entanto, nenhum marcador específico foi encontrado.

\section{CONCLUSÃO}

Embora seja uma doença rara, dada sua baixa incidência, apresenta quadro importante, com acometimento ósseo e, possivelmente, de outros órgãos. Portanto, destaca-se a importância da OCMR no diagnóstico diferencial de artropatias crônicas da infância e adolescência.
3. Surendra G, Shetty U. Chronic recurrent multifocal osteomyelitis: A rare entity. Journal Of Medical Imaging And Radiation Oncology. 2015; 59(4):436-444.

10.1111/1754-9485.12311. PMid: 25898848.

4. Gicchino MF, Diplomatico M, Granato C, et al. Chronic recurrent multifocal osteomyelitis: a case report. Italian Journal Of Pediatrics. 2018;44(1):1-5. Doi:10.1186/s13052018-0463-3. PMid: 29454377.

5. Girschick HJ, Zimmer C, Klaus G, et al. Chronic recurrent multifocal osteomyelitis: what is it and how should it be treated. Nature Clinical Practice Rheumatology. 2007; 3(12):733-738.

Doi:10.1038/ncprheum0653. PMid: 18037933.

6. Beck $\mathrm{C}$, Morbach $\mathrm{H}$, Beer $\mathrm{M}$, et al. Chronic nonbacterial osteomyelitis in childhood: prospective follow-up during the first year of anti-inflammatory treatment. Arthritis Research \& Therapy. 2010; 12(2):1-11.

Doi: $10.1186 /$ ar2992.

PMid: 20433730.

7. Taddio A, Zennaro F, Pastore $S$, et al. An Update on the Pathogenesis and Treatment of Chronic Recurrent Multifocal Osteomyelitis in Children. Pediatric Drugs. 2017; 19(3):165-172.

Doi: $10.1186 / a r 2992$.

PMid: 28401420.

8. von Kalle $T$, Heim N, Hospach $T$, et al. Typical Patterns of Bone Involvement in Whole-Body MRI of Patients with Chronic Recurrent Multifocal Osteomyelitis (CRMO). RöFo Fortschritte Auf Dem Gebiet Der Röntgenstrahlen Und Der Bildgebenden Verfahren. 2013; 185(07):655-661. Doi: $10.1055 / \mathrm{s}-0033-1335283$.

PMID: 23696017.

9. Jansson A, Renner ED, Ramser J, et al. Classification of NonBacterial Osteitis: Retrospective study of clinical, immunological and genetic aspects in 89 patients. Rheumatology. 2007; 46(1):154-160.

Doi:10.1093/rheumatology/kel190. PMid: 16782988.

10. Morbach $\mathrm{H}$, Hedrich $\mathrm{CM}$., Beer $\mathrm{M}$, et al. Autoinflammatory bone disorders. Clinical Immunology. 2013; 147(3):185-196. Doi: 10.1016/j.clim.2012.12.012. PMid: 23369460.

\section{REFERÊNCIAS BIBLIOGRÁFICAS}

1. Campos TA, Rebelo J, Maia A, et al. Osteomielite Multifocal Crónica Recorrente: Uma Entidade a Reconhecer. Arquivos de Medicina. 2011; 25(5):183-185.

2. Hoffman SR, Kapplusch F, Girschick HJ, et al. Chronic Recurrent Multifocal Osteomyelitis (CRMO): presentation, pathogenesis, and treatment. Current Osteoporosis Reports. 2017; 15(6):542-554. Doi: 10.1007/s11914-017-0405-9. PMid: 29080202 